\title{
Alternative Medicine: Implications on Dentistry
}

\section{Ola Moustafa Omar*}

Department of Pediatric and Community Dentistry, Cairo University, Egypt

Natural products have been used for several years in folk medicine. Over the last decade herbal medications in both prophylaxis and treatment of various diseases turned to be a popular form of therapy throughout the world. Many side effects associated with traditional medicines have been averted by using herbal medicines and thus they are safer to use.

Some of the commonly marketed pharmaceutical drugs are derived from herbs, like aspirin which is derived from white willow bark and digitalis which is derived from foxglove.

Herbal medicines are drugs of plant origin and are referred to as alternative medicine. Many herbal medicines have been proven to be beneficial in treatment of various medical conditions. However, the effect of herbal products on oral tissues, their mechanism of action and side effects are lacking sufficient evidence.

Several natural products are marketed for oral and dental use to satisfy the shift to usage of natural products from pharmaceutical products among the public. These alternative products can be either dental products with natural ingredients or herbal products. Different herbs have been included in dental products as: Bloodroot, Carawy, Chamomile, Echinacea, Peppermint, Rosemary, Thyme, Aloe vera, Green tea, Fennel, Ginger, Salvadora persica (miswak extract), Clove oil, Eucalyptus and Nigella sativa oil.

Toothpastes and oral rinses are usually marketed as cosmetic products. Both products are used to maintain good oral hygiene and counteract bad breath. Poor oral hygiene result in plaque accumulation which is a major etiological factor in occurrence of dental caries and gingival and periodontal diseases.

Toothpaste containing a herbal formulation (Aloe vera) decrease plaque accumulation and improve gingival condition. Sanguinaria extract, a derivative of Sanguinaria canadensis (bloodroot) has been incorporated in oral rinse and toothpaste products to control bad breath and have proved to be effective. Herbal mouthwashes and toothpastes containing miswak extract that decrease plaque accumulation and gingival inflammation.

Green tea contains chemical ingredients such as polyphenols which possess antimicrobial, anti-inflammatory and anti-cariogenic effects. Oral rinsing with green tea decreases the number of cariogenic bacteria significantly and also decreases acidity of plaque and saliva as well. It can be used as a cost-effective caries preventive measure in developing countries.

Oil extracts from plants have been successfully used in treatment of various diseases. Nigella sativa is an annual herbaceous branched plant widely distributed in countries bordering the Mediterranean Sea, Middle Europe and Western Asia. The seeds of Nigella sativa are known in Arabic countries as Al-Habbah al-sawda (black corn) or Habet EI Baraka (corn of blessing). Black seed oil has shown to possess the following medical effects: bronchodilator, immune-potentiating activity, hypotensive, analgesic, antibacterial and anti-inflammatory. It has proven effective in reducing the severity of chemotherapy induced oral mucositis in albino rats. In dentistry, Nigella sativa possesses an anti-inflammatory effect on the dental pulp and thus can be used as a pulp medicament in clinical practice.

Although several herbal products have been tested, yet conclusive results are still lacking. Researchers should be encouraged to conduct controlled studies to prove the effectiveness and safety of natural dental products. Those studies will provide dentists with sufficient clinical evidence before prescribing promoted natural products for their patients.
*Corresponding author: Ola Moustafa Omar, Department of Pediatric and Community Dentistry, Cairo University, Egypt, E-mail: omaromo@yahoo.com

Received December 12, 2012; Accepted December 12, 2012; Published December 14, 2012

Citation: Omar OM (2013) Alternative Medicine: Implications on Dentistry. Altern Integ Med 1:e103. doi:10.4172/2327-5162.1000e103

Copyright: (c) 2013 Omar OM. This is an open-access article distributed unde the terms of the Creative Commons Attribution License, which permits unrestricted use, distribution, and reproduction in any medium, provided the original author and source are credited. 